\title{
PENGARUH ATRIBUT PRODUK TERHADAP KEPUTUSAN PEMBELIAN SEPEDA MOTOR HONDA SCOOPY PADA MAHASISWA DI UNIVERSITAS TADULAKO
}

\author{
Rahmawati \\ Rosida P. Adam \\ Maskuri Sutomo \\ Jurusan Manajemen, Fakultas Ekonomi, Universitas Tadulako \\ Email: rahmawatihbasri@gmail.com
}

\begin{abstract}
This study aims to determine the influence of attribute product on purchase decision of Honda Scoopy motorcycles of students in Tadulako University. The type of study is descriptive causal. Sample consists of 96 respondents who selected by applying purposive sampling technique. Data analysis is multiple linear regressions. The results show that product attributes consist of brand, product quality, product features, product design, service, warranty, and price simultaneously have significant influence on purchasing decision of Honda Scoopy motorcycles of students in Tadulako University; brand partially has significant influence on purchase decision of Honda Scoopy motorcycles of students in Tadulako University; product quality partially has significant influence on purchase decision of Honda Scoopy motorcycles of students in Tadulako University; product features partially have significant influence on purchase decision of Honda Scoopy motorcycles of students in Tadulako University; design partially has significant influence on purchase decision of Honda Scoopy motorcycles of students in Tadulako University; service partially has non-significant influence on purchase decision of Honda Scoopy motorcycles of students in Tadulako University; warranty partially has significant influence on purchase decision of Honda Scoopy motorcycles of students in Tadulako University; price partially has significant influence on purchase decision of Honda Scoopy motorcycle of students in Tadulako University.
\end{abstract}

Keywords: product attribute, decision of purchase

ABSTRAK

Penelitian ini bertujuan untuk mengetahui pengaruh atribut produk terhadap keputusan pembelian sepeda motor Honda Scoopy pada mahasiswa Universitas Tadulako. Metode yang digunakan adalah metode deskriptif kausal. Sampel berjumlah 96 responden dengan teknik pengambilan purposive sampling. Metode analisis data yang digunakan dalam penelitian ini adalah analisis regresi linear berganda. Hasil penelitian menunjukkan bahwa atribut produk yang terdiri dari merek kualitas produk, fitur produk, desain produk, pelayanan, garansi dan harga secara simultan berpengaruh signifikan terhadap keputusan pembelian sepeda motor Honda Scoopy pada mahasiswa Universitas Tadulako. Selanjutnya variabel merek secara parsial berpengaruh signifikan terhadap keputusan pembelian sepeda motor Honda Scoopy pada mahasiswa Universitas Tadulako, kualitas produk secara parsial berpengaruh signifikan terhadap keputusan pembelian sepeda motor Honda Scoopy pada mahasiswa Universitas Tadulako, fitur produk secara parsial berpengaruh signifikan terhadap pembelian sepeda motor Honda Scoopy pada mahasiswa Universitas Tadulako, Desain secara parsial berpengaruh signifikan terhadap keputusan pembelian sepeda motor Honda Scoopy pada mahasiswa Universitas Tadulako, Pelayanan secara parsial berpengaruh tidak signifikan terhadap keputusan pembelian sepeda motor Honda Scoopy pada mahasiswa Universitas Tadulako, Garansi secara parsial berpengaruh signifikan terhadap keputusan pembelian sepeda motor Honda Scoopy pada mahasiswa Universitas Tadulako, dan Harga secara parsial berpengaruh signifikan terhadap keputusan pembelian sepeda motor Honda Scoopy pada mahasiswa Universitas Tadulako.

Kata Kunci: Atribut produk, Keputusan pembelian kembali. 


\section{PENDAHULUAN}

Atribut produk menjadi pertimbangan konsumen untuk melakukan pembelian atas produk dan mempunyai pengaruh terhadap keputusan pembelian konsumen. Keputusan pembelian konsumen merupakan salah satu hal penting yang harus diperhatikan oleh pemasar. Banyak produk-produk bermunculan mengharuskan pemasar sebagai pihak yang menawarkan berbagai produk kepada konsumen dapat menganalisis faktor-faktor yang menjadi dasar perilaku keputusan konsumen dalam melakukan pembelian produk. Menurut Tjiptono (2008:21) Keputusan pembelian adalah sebuah proses dimana konsumen mengenal masalahnya, mencari informasi mengenai produk atau merek tertentu dan mengevaluasi seberapa baik masing-masing alternatif tersebut dapat memecahkan masalahnya, yang kemudian mengarah kepada keputusan pembelian.

Atribut produk juga dipandang penting oleh PT. Astra Honda Motor yang merupakan pelopor industri sepeda motor di Indonesia, sebagai produsen sepeda motor bermerek Honda yang memproduksi motor jenis matic, yaitu Honda Scoopy, yang dirilis sejak tahun 2010 dan mendapat pembaharuan pada oktober 2014. Seperti diketahui bahwa skutik ini memiliki tampilan yang berbeda dengan skutik-skutik lainnya karena sangat kental dengan aliran retro modern. Meskipun skutik Honda Scoopy ini diciptakan khusus untuk kelas segmented alias hanya kalangan tertentu yaitu tepatnya kaum wanita, namun siapa sangka penjualan Honda Scoopy ini sanggup memberikan angka penjualan yang cukup besar dan memuaskan.

Merek Honda Scoopy sendiri sudah dikenal di masyarakat, karena bentuk desainnya yang unik. Honda Scoopy hadir sebagai generasi penerus dari Honda Scoopy dengan mengusung tampilan baru yang dipadukan dengan Honda Smart Technology dan berbagai fitur terbaik di kelasnya. Perubahan tersebut membuat motor skutik retro Honda Scoopy semakin terlihat lebih mewah, ramah lingkungan serta hemat bahan bakar (BBM). Harga Honda Scoopy dibanderol dengan harga Rp 18.500.000,untuk semua tipe. Berdasarkan uraian tersebut, apakah tampilan Honda Scoopy dalam hal ini atribut produk dapat mempengaruhi keputusan pembelian konsumen. Untuk itu perlu dilakukan penelitian dengan tujuan untuk mengetahui dan menganalisa:

1. Pengaruh simultan variabel atribut produk yang terdiri dari merek, kualitas produk, fitur produk, desain produk, pelayanan produk, jaminan dan harga terhadap keputusan pembelian sepeda motor Honda Scoopy.

2. Pengaruh merek terhadap keputusan pembelian sepeda motor Honda Scoopy.

3. Pengaruh kualitas produk terhadap keputusan pembelian sepeda motor Honda Scoopy.

4. Pengaruh fitur produk terhadap keputusan pembelian sepeda motor Honda Scoopy.

5. Pengaruh desain produk terhadap keputusan pembelian sepeda motor Honda scoopy.

6. Pengaruh pelayanan terhadap keputusan pembelian sepeda motor Honda scoopy.

7. Pengaruh garansi terhadap keputusan pembelian sepeda motor Honda scoopy.

8. Pengaruh harga terhadap keputusan pembelian sepeda motor Honda scoopy.

\section{KAJIAN LITERATURE}

\section{Pemasaran}

Pemasaran Menurut Kotler dan Armstrong (2008:6) adalah proses dimana perusahaanmenciptakan nilai bagi pelanggan dan membangun hubungan yang kuat dengan pelanggan dengan tujuan untuk menangkap nilai dari pelanggan sebagai imbalannya. Menurut Kotler dan Keller (2009:5) pemasaran adalah adalah suatu sistem keseluruhan dari kegiatan bisnis yang ditujukan untuk merencanakan, menetukan harga, mempromosikan dan mendistribusikan barang dan jasa yang memuaskan kebutuhan baik kepada pembeli maupun kepada pembeli potensial. American Marketing Association (AMA) mendefinisikan Pemasaran sebagaisuatu fungsi organisasi dan serangkaian proses untuk menciptakan,mengkomunikasikan, dan memberikan nilai kepada pelanggan dan untuk mengelola 
hubungan pelanggan dengan cara yang menguntungkan organisasi dan pemangku kepentingannya (Kotler dan Keller, 2009:5).

\section{Perilaku Konsumen}

Kotler dan Keller (2009:166) memaparkan pengertian dari perilaku konsumen sebagai studi tentang bagaimana individu, kelompok, dan organisasi memilih membeli, menggunakan, dan bagaimana barang, jasa, ide, atau pengamalan untuk memuaskan kebutuhan dan keinginan mereka. Menurut Sunyoto (2015:4) perilaku konsumen adalah tindakan-tindakan yang dilakukan oleh individu, kelompok, atau organisasi yang berhubungan dengan proses pengambilan keputusan dalam mendapatkan, menggunakan barang-barang atau jasa ekonomis yang dapat dipengaruhi lingkungan. Swasta dan Handoko (20007:10) mengartikan perilaku konsumen sebagai kegiatan-kegiatan individu yang secara langsung terlibat dalam mendapatkan dan menggunakan barang-barang dan jasa termasuk didalamnya proses pengambilan keputusan padapersiapan dan penentuan kgiatan tersebut.

\section{Atribut Produk}

Atribut produk Menurut Kotler dan Armstrong (2008:272) adalah pengembangan suatu produk atau jasa melibatkan pendefinisian manfaat yang akan ditawarkan produk atau jasa tersebut. Manfaat ini dikomunikasikan dan dihantarkan oleh atribut produk seperti kualitas produk, fitur produk, serta gaya dan desain produk. Atribut Produk menurut Tjiptono (2008:103) adalah unsur-unsur yang dipandang penting oleh konsumen dan dijadikan dasar pengambilan keputusan pembelian, yang meliputi Merek, kemasan, label, pelayanan, Jaminan (garansi), dan sebagainya.

Menurut Peter dan Olson (2014:189) produk dan atribut produk adalah stimulus utama yang memengaruhi afeksi, kognisi, dan perilaku konsumen. Pemasaran dan informasi lain juga memengaruhi pembelian dan penggunaan produk akan memuaskan atau tidak. Peter dan Olson juga mengemukakan atribut produk meliputi harga, desain, warna, kualitas, dan merek.

\section{Keputusan Pembelian}

Menurut Tjiptono (2008:21) Keputusan pembelian adalah sebuah proses dimana konsumen mengenal masalahnya, mencari informasi mengenai produk atau merek tertentu dan mengevaluasi seberapa baik masing-masing alternatif tersebut dapat memecahkan masalahnya, yang kemudian mengarah kepada keputusan pembelian. Keputusan pembelian adalah keputusan pembeli tentang merek mana yang dibeli (Kotler dan Amstrong, 2012:181). Pengertian lain keputusan pembelian adalah keputusan konsumen mengenai preferensi atas merek-merek yang ada di dalam kumpulan pilihan (Kotler dan Keler, 2009:240). Menurut Swastha dan Handoko (2008:110) keputusan pembelian merupakan proses dalam pembelian yang nyata, apakah membeli atau tidak. Dari berbagai faktor yang mempengaruhi konsumen dalam melakukan pembelian suatu produk atau jasa, biasanya konsumen selalu mempertimbangkan kualitas, harga, dan produk yang sudah dikenal masyarakat.

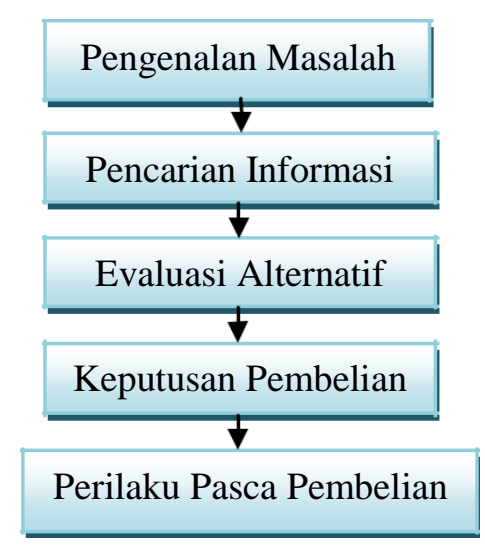

Gambar 1 Proses Pembelian Konsumen Model Lima Tahap 


\section{Kerangka Pemikiran}

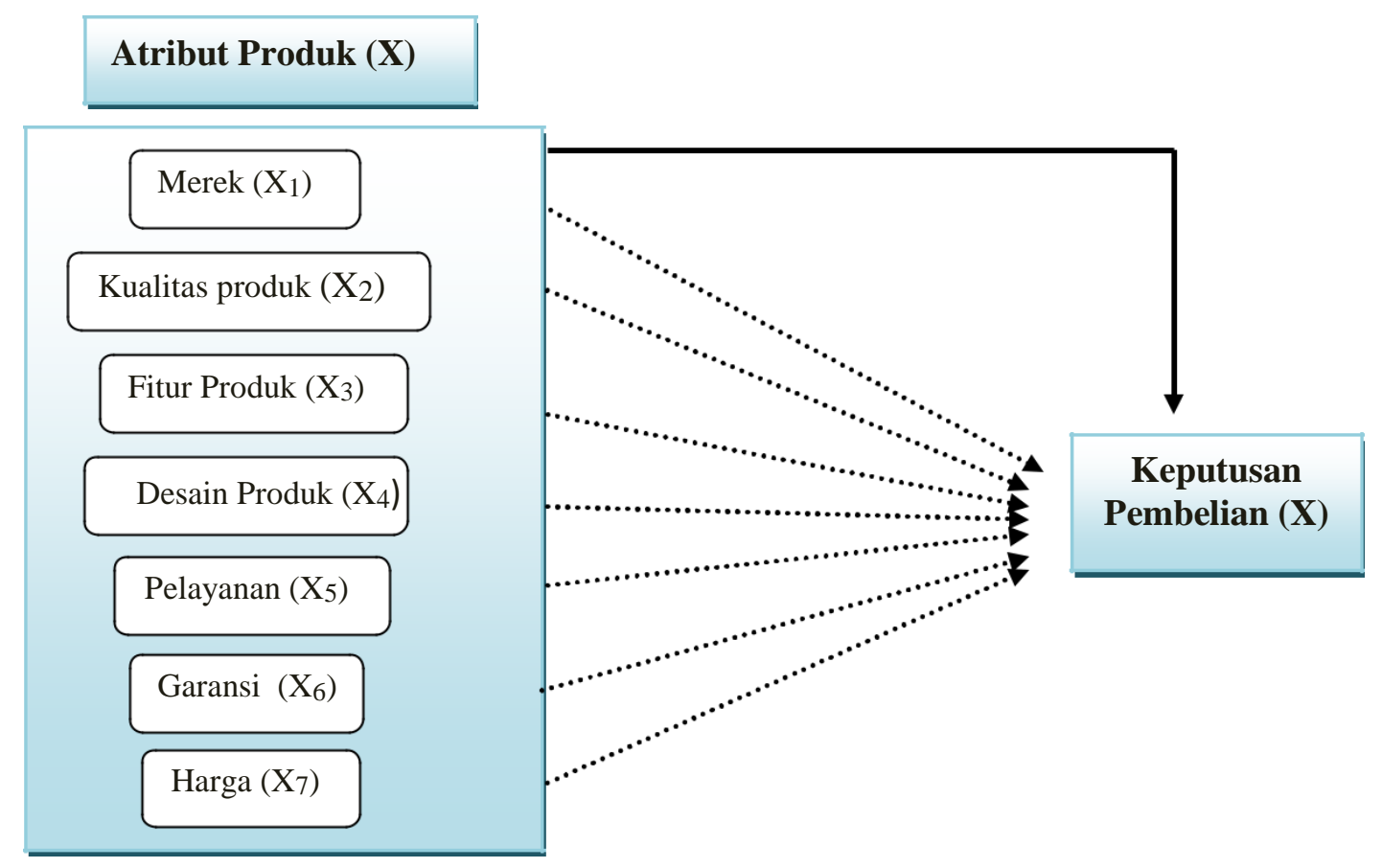

\section{Hipotesis}

\section{Gambar 2 Kerangka pemikir}

Berdasarkan teori dan kerangka berpikir di atas dapat disusun beberapa hipotesis sebagai berikut:

1. Atribut produk yang terdiri dari merek, kualitas produk, fitur produk, desain produk, pelayanan, jaminan, dan harga secara simultan berpengaruh signifikan terhadap keputusan pembelian sepeda motor Honda Scoopy.

2. Merek berpengaruh signifikan terhadap keputusan pembelian sepeda motor Honda Scoopy.

3. Kualitas produk berpengaruh signifikan terhadap keputusan pembelian sepeda motor Honda Scoopy.

4. Fitur produk berpengaruh signifikan terhadap keputusan pembelian sepeda motor Honda Scoopy.

5. Desain produk berpengaruh signifikan terhadap keputusan pembelian sepeda motor Honda Scoopy.

6. Pelayanan berpengaruh signifikan terhadap keputusan pembelian sepeda motor Honda Scoopy.

7. Garansi berpengaruh signifikan terhadap keputusan pembelian sepeda motor Honda Scoopy.

8. Harga berpengaruh signifikan terhadap keputusan pembelian sepeda motor Honda Scoopy.

\section{METODE PENELITIAN}

Jenis penelitian yang digunakan yaitu gabungan dari deskriptif kausal. Penelitian deskriptif menurut Sangadji dan Sopiah (2010: 21) adalah penelitian terhadap masalah-masalah berupa faktafakta saat ini dari suatu populasi yang meliputi kegiatan penilaian sikap atau pendapat terhadap indiviidu, organisasi, keadaan, ataupu prosedur. Teknik pengumpulan data dengan pengamatan (wawancara atau kuesioner) yang tidak mendalam, dan hasil penelitian cenderung untuk digeneralisasikan.

Populasi dalam penelitian ini adalah mahasiswa sebagai konsumen yang menggunakan sepeda motor Honda Scoopy di Universitas Tadulako. Teknik pengambilan sampel untuk menentukan sampel yang akan digunakan dalam penelitian ini menggunakan Teknik non probability 
sampling, yaitu purposive sampling. Purposive sampling adalah cara pengambilan sampel berdasarkan karakteristik tertentu.

Jumlah sampel dalam penelitian ini merujuk pada Teori Roscoe (Sugiyono, 2013:102) yaitu jumlah anggota sampel minimal 10 kali dari jumlah variabel yang diteliti. Jumlah variabel dalam penelitian ini adalah 8 yang terdiri dari variabel independen Merek, kualitas produk, fitur produk, desain produk, pelayanan, jaminan dan Harga, serta variabel dependen yaitu keputusan pembelian. Dengan pertimbangan variabel pada penelitian ini hanya berjumlah 8 variabel, maka peneliti menentukan sampel 10 kali jumlah variabel. Berdasarkan pertimbangan tersebut maka penulis memetapkan jumlah sampel dengan ketentuan 12 × 8 variabel yaitu 96 responden, dengan demikian sampel dari penelitian ini adalah 96 orang.

Penelitian ini menggunakan aplikasi software SPSS (Statistical Program for Social Scane) versi 16.0 yang dipakai untuk menganalisis pengaruh secara simultan dan pengaruh secara parsial variabel citra merek dan komitmen terhadap pembelian kembali. Adapun teknik analisis data yang dipergunakan dalam penelitian ini, yaitu analisis deskriptif dan regresi linier berganda. Sugiyono (2014:277) menjelaskan bahwa model umum bentuk persamaan alat analisis statistic parametric regresi linear berganda dapat digambarkan sebagai berikut:

$$
\mathrm{Y}=\mathrm{a}+\mathrm{b}_{1} \mathrm{X}_{1}+\mathrm{b}_{2} \mathrm{X}_{2}+\mathrm{b}_{3} \mathrm{X}_{3}+\mathrm{b}_{4} \mathrm{X}_{4}+\mathrm{b}_{5} \mathrm{X}_{5}+\mathrm{b}_{6} \mathrm{X}_{6}+\mathrm{b}_{7} \mathrm{X}_{7}+\mathrm{e}
$$

Di mana:

$\mathrm{Y}=$ Keputusan Konsumen

$\mathrm{X}_{1}=$ Merek

$\mathrm{X}_{2}=$ Kualitas produk

$\mathrm{X}_{3}=$ Fitur produk

$\mathrm{X}_{4}=$ Desain produk

$\mathrm{X}_{5}=$ Pelayanan

$\mathrm{X}_{6}=$ Garansi

$\mathrm{X}_{7}=$ Harga

$\mathrm{A}=$ Konstanta

$\mathrm{b}_{1-} \mathrm{b}_{2}=$ Koefisien Regresi

\section{HASIL DAN PEMBAHASAN}

\section{Analisis Regresi Berganda}

Tabel 1 Ringkasan Hasil Uji Regresi Berganda

\begin{tabular}{|c|c|c|c|c|c|}
\hline \multicolumn{6}{|c|}{ Dependen Variabel Y = Keputusan Pembelian } \\
\hline \multirow[t]{2}{*}{ Variabel Independen } & \multicolumn{2}{|c|}{$\begin{array}{c}\text { Unstandardized } \\
\text { Coefficients }\end{array}$} & \multirow{2}{*}{$\begin{array}{c}\begin{array}{c}\text { Standardized } \\
\text { Coefficients }\end{array} \\
\text { Beta }\end{array}$} & \multirow[t]{2}{*}{$\mathbf{T}$} & \multirow[t]{2}{*}{ Sig } \\
\hline & $\overline{\mathbf{B}}$ & $\begin{array}{c}\text { Standar } \\
\text { Error }\end{array}$ & & & \\
\hline $\mathrm{C}=$ Constanta & .191 & .351 & & .545 & .587 \\
\hline $\operatorname{Merek}\left(\mathrm{X}_{1}\right)$ & -.034 & .095 & -.294 & -3.201 & .002 \\
\hline Kualitas Produk $\left(\mathrm{X}_{2}\right)$ & .479 & .080 & .479 & 5.967 & .000 \\
\hline Fitur Produk $\left(\mathrm{X}_{3}\right)$ & -.219 & .073 & -.258 & -2.996 & .004 \\
\hline Desain Produk $\left(\mathrm{X}_{4}\right)$ & .225 & .112 & .205 & 2.006 & .048 \\
\hline Pelayanan $\left(\mathrm{X}_{5}\right)$ & .029 & .039 & .045 & .728 & .469 \\
\hline Garansi (X6) & .527 & .076 & .566 & 6.951 & .000 \\
\hline Harga $\left(X_{7}\right)$ & .213 & .096 & .188 & 2.215 & .029 \\
\hline $\begin{array}{lll}\text { Multiple R } & =.836 \\
\mathrm{R} \text { Square }\left(\mathrm{R}^{2}\right) & =.699\end{array}$ & & Sig.F & & & \\
\hline
\end{tabular}


Berdasarkan hasil tersebut apabila ditulis dalam bentuk standardized dari persamaan regresinya adalah sebagai berikut:

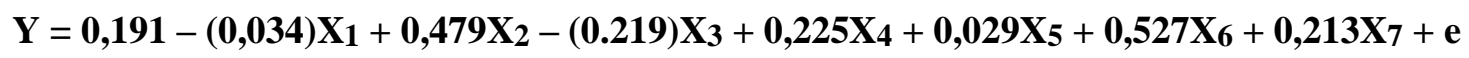

\section{Pembahasan}

\section{Pengujian Hipotesis Pertama (Uji F)}

Berdasarkan Tabel diatas, diperoleh angka signifikansi F sebesar 0,000. Angka 0,000 $<0,05$ oleh karena itu, Ho ditolak dan Ha diterima. Artinya adanya pengaruh signifikan variabel kualitas produk $\left(\mathrm{X}_{1}\right)$ dan citra merek $\left(\mathrm{X}_{2}\right)$ terhadap keputusan konsumen (Variabel $\left.\mathrm{Y}\right)$.

\section{Pengujian Hipotesis (Hasil Uji t)}

1. Variabel Merek $\left(\mathrm{X}_{1}\right)$

Berdasarkan Tabel, hasil pengujian dengan SPSS diperoleh angka signifikansi sebesar 0,002. Angka $0,002<0,05$ oleh karena itu, hipotesis diterima. Hal ini berarti variabel $\mathrm{X}_{1}$ (merek) berpengaruh terhadap variabel Y (keputusan konsumen).

2. Variabel Kualitas Produk $\left(\mathrm{X}_{2}\right)$

Berdasarkan Tabel, hasil pengujian dengan SPSS angka signifikansi sebesar 0,000. Angka 0,000 < 0,05 oleh karena itu, hipotesis diterima. Hal ini berarti variabel $\mathrm{X}_{2}$ (kualitas produk) berpengaruh terhadap variabel Y (keputusan konsumen).

3. Variabel Fitur Produk $\left(\mathrm{X}_{3}\right)$

Berdasarkan Tabel, hasil pengujian dengan SPSS angka signifikansi sebesar 0,004. Angka 0,004< 0,05 oleh karena itu, hipotesis diterima. Hal ini berarti variabel $\mathrm{X}_{3}$ (fitur produk) berpengaruh terhadap variabel $\mathrm{Y}$ (keputusan konsumen).

4. Variabel Desain Produk $\left(\mathrm{X}_{4}\right)$

Berdasarkan Tabel, hasil pengujian dengan SPSS angka signifikansi sebesar 0,048. Angka 0,048< 0,05 oleh karena itu, hipotesis diterima. Hal ini berarti variabel $\mathrm{X}_{4}$ (desain produk) berpengaruh terhadap variabel Y (keputusan konsumen).

5. Variabel Pelayanan $\left(\mathrm{X}_{5}\right)$

Berdasarkan Tabel, hasil pengujian dengan SPSS angka signifikansi sebesar 0,469. Angka 0,469< 0,05 oleh karena itu, hipotesis diterima. Hal ini berarti variabel $\mathrm{X}_{5}$ (pelayanan) berpengaruh terhadap variabel Y (keputusan konsumen).

6. Variabel Garansi (X6)

Berdasarkan Tabel, hasil pengujian dengan SPSS angka signifikansi sebesar 0,000. Angka 0,000 < 0,05 oleh karena itu, hipotesis diterima. Hal ini berarti variabel $\mathrm{X}_{6}$ (garansi) berpengaruh terhadap variabel Y (keputusan konsumen).

7. Variabel Harga $\left(\mathrm{X}_{7}\right)$

Berdasarkan Tabel, hasil pengujian dengan SPSS angka signifikansi sebesar 0,029. Angka 0,029< 0,05 oleh karena itu, hipotesis diterima. Hal ini berarti variabel $\mathrm{X}_{7}$ (harga) berpengaruh terhadap variabel Y (keputusan konsumen).

\section{KESIMPULAN DAN SARAN Kesimpulan}

1. Atribut produk yang terdiri dari merek, kualitas produk, fitur produk, desain produk, pelayanan, garansi dan harga, secara simultan berpengaruh signifikan terhadap keputusan pembelian sepeda motor Honda Scoopy pada mahasiswa di Universitas Tadulako.

2. Merek secara parsial berpengaruh signifikan terhadap keputusan pembelian sepeda motor Honda Scoopy pada Mahasiswa di Universitas Tadulako. 
3. Kualitas produk secara parsial berpengaruh signifikan terhadap keputusan pembelian sepeda motor Honda Scoopy pada Mahasiswa di Universitas Tadulako.

4. Fitur produk secara parsial berpengaruh signifikan terhadap keputusan pembelian sepeda motor Honda Scoopy pada Mahasiswa di Universitas Tadulako.

5. Desain produk secara parsial berpengaruh signifikan terhadap keputusan pembelian sepeda motor Honda Scoopy pada Mahasiswa di Universitas Tadulako.

6. Pelayanan secara parsial berpengaruh tidak signifikan terhadap keputusan pembelian sepeda motor Honda Scoopy pada Mahasiswa di Universitas Tadulako.

7. Garansi secara parsial berpengaruh signifikan terhadap keputusan pembelian sepeda motor Honda Scoopy pada Mahasiswa di Universitas Tadulako.

8. Harga secara parsial berpengaruh signifikan terhadap keputusan pembelian sepeda motor Honda Scoopy pada Mahasiswa di Universitas Tadulako.

\section{Saran}

1. Pada variabel merek diperoleh indikator terendah yaitu banyak diminati. Sebaiknya pihak perusahaan harus dapat melakukan lebih mengembangkan inovasi merek dari Honda Scoopy sehingga peminat dari Honda Scoopy akan lebih bertambah lagi. Sehingga para konsumen akan memutuskan untuk membeli Honda Scoopy.

2. Dari variabel kualitas produk diperoleh indikator terendah adalah konsumsi bahan bakar. Dari itu untuk pihak perusahaan diharapkan agar dapat menigkatkan kualitas produknya misalnya dengan lebih mengembangkan teknologi pada mesin motor sehingga akan membuat konsumsi bahan bakar akan lebih irit.

3. Dari variabel fitur diperoleh indikator terendah yaitu dilengkapi dengan fitur keamanan yang canggih. Honda Scoopy mengusung beberapa fitur unggulan yang semakin keren dan canggih, untuk saran selanjutnya agar mempertahankan atau mengurangi fitur-fitur yang dianggap kurang penting sehingga konsumen akan merasa lebih nyaman dengan fitur yang ada.

4. Dari variabel desain diperoleh indikator terendah yaitu pilihan warna yang menarik. Honda Scoopy mengusung tiga tipe, dan masing-masing tipe hanya mempunyai kurang lebih tiga warna. Untuk itu disarankan agar pihak perusahaan memberikan lebih banyak lagi pilihan warna dari setiap tipe motor yang ada. Sehingga lebih menambah ketertarikan konsumen.

5. Dari variabel pelayanan diperoleh indikator terendah yaitu pelayanan service gratis. Pihak perusahaan juga harus lebih meningkatkan lagi pelayanan yang diberikan baik saat pembelian maupun purna pembelian, sehingga konsumen akan lebih memperhatikan dan merasa nyaman dengan pelayanan yang diberikan oleh perusahaan

6. Dari variabel garansi diperoleh indikator terndah yaitu garansi mesin. Pihak perusahaan Honda diharapkan dapat mempertahankan serta meningkatkan kinerja terhadap garansi, karena garansi sangat penting dan merupakan kekuatan yang dapat menggambarkan bagus atau tidakya sebuah perusahaan dalam melindungi dan melayani konsumen.

7. Pada variabel harga diperoleh indikator terendah yaitu daya saing harga dengan produk sejenis. Untuk meningkatkan daya saing, maka perusahaan harus memperhatikan masalah inovasi produk karena memberikan pengaruh terkecil terutama dalam hal inovasi dalam teknik pembuatan produk.

\section{REFERENSI}

Kotler, Philip dan Gary Armstrong. (2008). Prinsip-Prinsip Pemasaran, Edisi ke dua belas Jilid 1.

Penerbit PT. Indeks, Indonesia.

Kotler, dan Keller. (2008). Manajemen Pemasaran. Jilid Satu, Edisi 12, Cetakan Ke 3. Penerbit 
Indeks.

Kotler dan Keller. (2009). Manajemen Pemasaran, Jilid 1 Edisi ke 13. Jakarta: PT. Erlangga.

Peter, J.Paul dan Jerry C. Olson. (2014). Perilaku Konsumen \& Strategi pemasaran. Edisi 9 buku

2.Jakarta: Salembe Empat.

Sangadji, Etta Mamang dan Sopiah. (2010). Metode Penelitian. Yogyakarta: CV Andi Offset.

Sugiyono, (2013). Metode Penelitian Administrasi. Cetakan ke 21, Bandung: Alfabeta.

Sugiyono, (2014). Metode Penelitian Kuantitatif, Kualitatif, dan R\&D. Bandung: Alfabeta.

Sunyoto, Danang, (2015). Perilaku konsumen dan pemasaran: (Panduan Riset Sederhana untuk

Mengenali konsumen), cetakan pertama. Yogyakarta: CAPS ( Center Of Academic Publishing).

Swasta, Basu, dan Handoko, (2007). Manajemen Pemasaran. Cetakan pertama, Jakarta: PT. Pustaka LP3ES.

Tjiptono, Fandi. (2008). Strategi pemasaran, Yogyakarta: CV Andi Offset. 